\title{
Study of Fingerprint Pattern: A Cross Sectional Study
}

\author{
Vijay Kumar Ag$^{1}$, Suresh J. ${ }^{2}$ \\ ${ }^{1}$ Associate Professor, Department of Forensic Medicine \& Toxicology, Adichunchanagiri Institute of Medical \\ Sciences, ${ }^{2}$ Associate Professor, Department of Forensic Medicine \& Toxicology, J.J.M Medical College, Davangere
}

\begin{abstract}
A fingerprint is an impression left by the friction ridges of a human finger. The recovery of partial fingerprints from a crime scene is an important method of forensic science. Moisture and grease on a finger result in fingerprints on surfaces such as glass or metal. Objective: To determine the predominant fingerprint pattern in and around Mandya district. The present study was conducted at department of Forensic Medicine Adichunchanagiri Institute of Medical Sciences, Mandya from $1^{\text {st }}$ January to $31^{\text {st }}$ January 2019 . Total subjects included were 50 Male and 50 Female students. Subjects who were healthy and having normal hands were included in the study. In present study the Ulnar loop was the most frequently observed pattern followed by Plain whorl, in the total subject population in all ten digits. The least frequently observed pattern in the total population were Simple arches, twinned loops, tented arches, radial loops, accidental types and Exceptional arches both in Male and Female. Fingerprints can be captured as graphical ridge and valley patterns. Because of their uniqueness and permanence, fingerprints emerged as the most widely used biometric identifier in the 2000s.
\end{abstract}

Keywords: Finger Prints, Loop, Whorls, Arches, Composite, Biometry.

\section{Introduction}

A fingerprint is an impression left by the friction ridges of a human finger. The recovery of partial fingerprints from a crime scene is an important method of forensic science. Moisture and grease on a finger result in fingerprints on surfaces such as glass or metal. Deliberate impressions of entire fingerprints can be obtained by ink or other substances transferred from the peaks of friction ridges on the skin to a smooth surface such as paper. Fingerprint records normally contain impressions from the pad on the last joint of fingers and thumbs, though fingerprint cards also typically record portions of lower joint areas of the fingers.

Human fingerprints are detailed, nearly unique, difficult to alter, and durable over the life of an individual,

\section{Corresponding Author:}

Dr. Suresh J.

Associate Professor, Department of Forensic Medicine \& Toxicology, J.J.M. Medical College, Davangere e-mail: drsureshjfm@gmail.com making them suitable as long-term markers of human identity. They may be employed by police or other authorities to identify individuals who wish to conceal their identity, or to identify people who are incapacitated or deceased and thus unable to identify themselves, as in the aftermath of a natural disaster.

In the Henry Classification System there are three basic fingerprint patterns: loop, whorl, and arch, which constitute 60-65 percent, 30-35 percent, and 5 percent of all fingerprints respectively. There are also more complex classification systems that break down patterns even further, into plain arches or tented arches, ${ }^{[5]}$ and into loops that may be radial or ulnar, depending on the side of the hand toward which the tail points. Ulnar loops start on the pinky-side of the finger, the side closer to the ulna, the lower arm bone. Radial loops start on the thumb-side of the finger, the side closer to the radius. Whorls may also have sub-group classifications including plain whorls, accidental whorls, double loop whorls, peacock's eye, composite, and central pocket loop whorls. ${ }^{1,2}$

Fingerprint identification, known as dactyloscopy, ${ }^{3}$ 
or hand print identification, is the process of comparing two instances of friction ridge skin impressions (see Minutiae), from human fingers or toes, or even the palm of the hand or sole of the foot, to determine whether these impressions could have come from the same individual. The flexibility of friction ridge skin means that no two finger or palm prints are ever exactly alike in every detail; even two impressions recorded immediately after each other from the same hand may be slightly different. Fingerprint identification, also referred to as individualization, involves an expert, or an expert computer system operating under threshold scoring rules, determining whether two friction ridge impressions are likely to have originated from the same finger or palm (or toe or sole).

Objective: To determine the predominant fingerprint pattern in and around Mandya district.

\section{Methodology}

The present study was conducted at department of Forensic Medicine Adichunchanagiri Institute of Medical Sciences, Mandya from $1^{\text {st }}$ January to $31^{\text {st }}$ January 2019. Total subjects included were 50 Male and 50 Female students. Subjects who were healthy and having normal hands were included in the study.

\section{Results}

In present study the Ulnar loop was the most frequently observed pattern followed by Plain whorl, in the total subject population in all ten digits. The least frequently observed pattern in the total population were Simple arches, twinned loops, tented arches, radial loops, accidental types and Exceptional arches both in Male and Female.

\section{Discussion}

In present study the Ulnar loop was the most frequently observed pattern followed by Plain whorl, in the total subject population in all ten digits. The least frequently observed pattern in the total population were Simple arches, twinned loops, tented arches, radial loops, accidental types and Exceptional arches both in Male and Female.

In 1823 Jan Evangelista Purkyně identified nine fingerprint patterns. The nine patterns include the tented arch, the loop, and the whorl, which in modern day forensics are considered ridge details. In 1880 Henry Faulds, a Scottish surgeon in a Tokyo hospital, published his first paper on the usefulness of fingerprints for identification and proposed a method to record them with printing ink. Returning to Great Britain in 1886, he offered the concept to the Metropolitan Police in London but it was dismissed at that time. Up until the early 1890 s police forces in the United States and on the European continent could not reliably identify criminals to track their criminal record. Francis Galton published a detailed statistical model of fingerprint analysis and identification in his 1892 book Finger Prints. He had calculated that the chance of a "false positive" (two different individuals having the same fingerprints) was about 1 in 64 billion.

Gangadhar. M.R, Rajashekara Reddy. K (1983) reported in a study that the basic finger pattern type loops $(57.11 \%)$ were common followed by whorls (27.89\%) and arches (15.00\%) in the general population with significant sex difference and insignificant bilateral difference. $^{4}$

Purkait R, (2003) observed in his comparative study on frequency of fingerprint patterns and variation in the ten digit classification on males (454 samples- 227 from each tribe) of Mundas and Lodhas, a tribal group of Midnapur district in West Bengal where Mundas exhibit higher frequency of whorl and loop patterns while loops are more frequent among Lodhas. ${ }^{5}$

Nithin V (2009) reported in his study on 250 males and 250 females of south Indian population most frequent fingerprint pattern as ulnar loop in the total population as well as in the sex wise distribution. ${ }^{6}$

Arabindbasu (1976) reported distributional trend oft he three principal pattern types having high frequency of loops, moderate whorls and low arches. ${ }^{7}$

\section{Conclusion}

Fingerprints can be captured as graphical ridge and valley patterns. Because of their uniqueness and permanence, fingerprints emerged as the most widely used biometric identifier in the 2000s. Automated fingerprint verification systems were developed to meet the needs of law enforcement and their use became more widespread in civilian applications. Despite being deployed more widely, reliable automated fingerprint verification remained a challenge and was extensively researched in the context of pattern recognition and image processing. The uniqueness of a fingerprint can be established by the overall pattern of ridges and valleys, 
or the logical ridge dicontinuities known as minutiae. In the 2000s minutiae features were considered the most discriminating and reliable feature of a fingerprint. Therefore the recognition of minutiae features became the most common basis for automated fingerprint verification. The most widely used minutiae features used for automated fingerprint verification were the ridge ending and the ridge bifurcation.

Ethical Clearance: Obtained from Institutional Ethical Committee.

Source of Funding: Self

Conflict of Interest: Nil

\section{References}

1. Henry, Edward R. (1900). "Classification and Uses of Finger Prints". London: George Rutledge \& Sons, Ltd.
2. Engert, Gerald J. "International Corner". Identification News. 1964;14(1);1-4

3. Ashbaugh, David R. Royal Canadian Mounted Police. Archived (PDF) from the original on May 23, 2013. Retrieved October 26, 2013.

4. Gangadhar MR, Rajashekara RK-“Finger Dermatoglyphics of Adikarnatakas: A Scheduled Caste Population of Mysore City, Karnataka, Manin India 1983;83(1 \& 2):183-193.

5. Purkait R. Fingerprint Classification: A comparative study among Mundas and Lodhas. JMFT 2003;14:31-32.

6. Nithin V. Study of fingerprint classification and their gender distribution among South Indian Population. Journal of Forensic and Legal Medicine. Nov 2009; 16(8):460-463.

7. Basu A. Digital dermatoglyphics of three caste groups of Mysore. Am. J. Phy. Anthrop 1976; 45(3):437-441. 